\title{
Breast abscess due to Actinomyces europaeus
}

\author{
W. A. Silva $\cdot$ A. M. Pinheiro $\cdot$ B. Jahns $\cdot$ K. Bögli-Stuber $\cdot$ S. Droz $\cdot$ \\ S. Zimmerli
}

Received: 24 January 2011/Accepted: 31 March 2011/Published online: 21 April 2011

(C) Springer-Verlag 2011

\begin{abstract}
Actinomyces europaeus was first described in 1997 as a new species causing predominantly skin and softtissue infections. Mastitis due to A. europaeus is an unusual condition. This article reports a case of primary breast abscess caused by A. europaeus in a postmenopausal woman.
\end{abstract}

\section{Keywords Actinomyces europaeus · Actinomycosis ·} Mastitis

\section{Introduction}

Actinomyces spp. normally colonizes mucous membranes particularly of the oral cavity, the colon, and the vagina.

\section{W. A. Silva · A. M. Pinheiro}

Federal University of Rio Grande do Norte,

University Hospital Onofre Lopes, Nilo Peçanha avenue 620,

P.O. Box 59012-300, Natal, RN, Brazil

e-mail: wallaceandrino@yahoo.com.br

A. M. Pinheiro

e-mail: aline_mpinheiro@yahoo.com.br

B. Jahns

Clinic for Gynecology, Inselspital, University Hospital and University of Bern, Freiburgstr. 3, 3010 Bern, Switzerland

e-mail: boriana.jahns@insel.ch

K. Bögli-Stuber $\cdot$ S. Droz $\cdot$ S. Zimmerli $(\varangle)$

Institute for Infectious Diseases, University of Bern,

Friedbuehlstr. 51, P.O. Box 61, 3010 Bern, Switzerland

e-mail: stefan.zimmerli@ifik.unibe.ch

\section{S. Droz}

e-mail: sara.droz@ifik.unibe.ch

\section{Present Address:}

K. Bögli-Stuber

Swissmedic, Hallerstrasse 7, 3000 Bern 9, Switzerland

e-mail: katja.boegli@swissmedic.ch
Disruption of the mucosa may lead to indolent infections characterized by a chronic course, progression across tissue boundaries, and formation of sinus tracts. Until recently, identification of Actinomyces spp. was based on phenotypic tests. With increasing use of genotypic analysis taxonomy has advanced and new species have been described in the past 15 years. The disease-causing potential of many of these newly described species and the associated range of clinical manifestations is, however, incompletely understood.

A. europaeus is a Gram-positive, nonmotile, non-sporeforming facultative anaerobic rod first described as new species in 1997 on the basis of 16S rRNA gene sequencing [1]. It was found to cause infections of the urinary tract and of skin and soft-tissue, notably abscesses, pilonidal sinus infection, and decubital ulcers [2]. In this article we report a case of primary breast abscess caused by A. europaeus in a postmenopausal woman.

\section{Case report}

A 67-year-old immunocompetent woman was admitted to the hospital because of a painful swelling and hyperemia of the left breast which had appeared 3 days earlier. There was no history of fever, nipple discharge, tooth problems, or lung or breast disease. She was not diabetic and was a non-smoker. Two months earlier, she had undergone uncomplicated open heart surgery to receive a prosthetic aortic valve for severe aortic stenosis.

On physical examination, the patient was afebrile and there were no signs of systemic disease. Her body mass index was $28.9 \mathrm{~kg} / \mathrm{m}^{2}$. There was a tender, fluctuating mass of $12 \mathrm{~cm}$ in the left breast. The overlying skin was infiltrated and erythematous. The margin of the inflamed skin 
reached within $2 \mathrm{~cm}$ of the sternotomy scar which was without signs of inflammation. Sternal compression was not painful.

Results of laboratory tests showed a hemoglobin level of $114 \mathrm{~g} / \mathrm{L}$, a WBC of $12.3 \mathrm{G} / \mathrm{L}$ without a left shift, a thrombocyte count of $117 \mathrm{G} / \mathrm{L}$, and a level of C-reactive protein of $35 \mathrm{mg} / \mathrm{L}$. A chest X-ray was normal and a computed tomography scan of the thorax showed no signs of infection of the sternum or of intrathoracic tissues. Blood cultures were negative. The clinically diagnosed breast abscess was incised and drained under general anesthesia. Pus and tissue samples were sent for microbiological examination and for histopathology. Postoperatively there was a tender mass of $12 \times 6 \mathrm{~cm}$ in the inferior half of the breast. The wound was left open and a drainage tube was inserted. Two days later, the patient was free from pain and was discharged on oral amoxicillin-clavulanic acid $1 \mathrm{~g}$ tid.

Histopathology showed adipose-tissue necrosis, no sulfur granules, and no evidence of malignancy. Gram stains of pus revealed many Gram-negative bacilli and Grampositive rods. Again, no sulfur granules were seen. Cultures grew Actinomyces spp. and a mixed anaerobic flora composed of Gram-negative rods and Gram-positive cocci that was not further characterized. A. europaeus was identified by full-length sequencing of the 16S rRNA gene by using MicroSeq Full Gene 16S rDNA PCR and sequencing kits (Applied Biosystems). BLAST analysis showed 99.7\% identity with the $16 \mathrm{~S}$ rRNA gene sequence of A. europaeus strain CCUG 32789A (GenBank accession no. NR_026363). The isolate was tested for susceptibility using the $E$ test (AB Biodisk, Solna, Sweden) with the following results: penicillin G MIC: $0.008 \mu \mathrm{g} / \mathrm{mL}$, amoxicillin MIC: $0.023 \mu \mathrm{g} / \mathrm{mL}$, ceftriaxone MIC: $0.047 \mu \mathrm{g} / \mathrm{mL}$, piperacillin-tazobactam MIC: $0.047 \mu \mathrm{g} / \mathrm{mL}$, clindamycin MIC: $0.016 \mu \mathrm{g} / \mathrm{mL}$, and tetracycline MIC: $0.380 \mu \mathrm{g} / \mathrm{mL}$. According to the Clinical and Laboratory Standards Institute criteria the isolate was susceptible to all tested antimicrobial agents [3].

After three weeks, under the assumption that the mixed anaerobic flora had been eliminated, treatment was changed to amoxicillin $2 \mathrm{~g}$ tid for 4 weeks followed by amoxicillin $1 \mathrm{~g}$ tid for the remainder of the treatment period. The breast remained non-tender and painless. The tissue mass, infiltrated skin, and wound secretions improved only very slowly. After three months, three draining sinuses secreting minimal amounts of pus developed on the inferior aspect of the breast (Fig. 1). The opening left by the abscess drainage healed by granulation after 10 months. The draining sinuses that were débrided regularly resolved after 15 months. At that time the antibiotic treatment was discontinued. At followup, 6 months later, there were no signs of recurrent

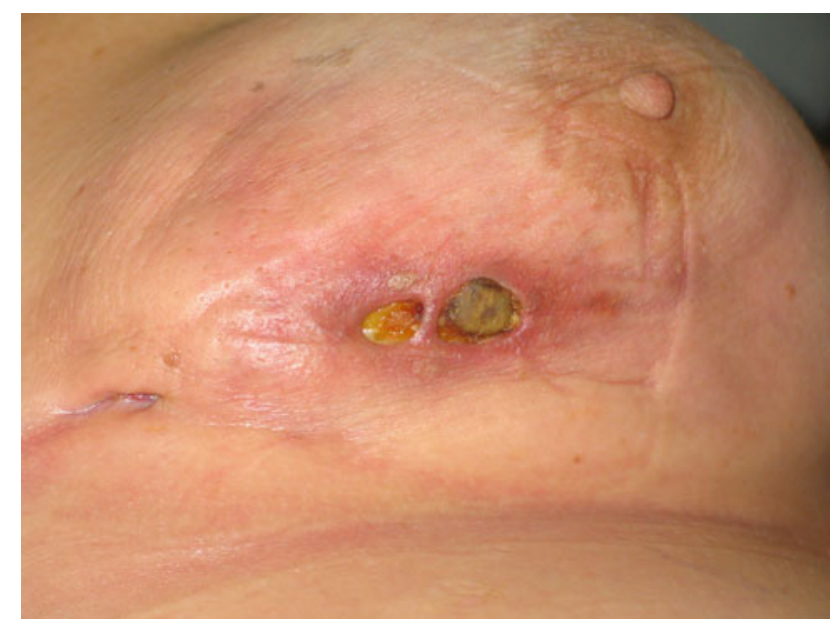

Fig. 1 Photograph of the patient's left breast 6 months after abscess drainage and start of antibiotic therapy. The incision wound on the medial aspect is healing, the mass in the inferior medial quadrant and erythematous skin have improved. On the inferior aspect draining sinuses that formed after 3 months of antibiotic therapy are covered by necrotic membranes that are regularly débrided. Eventual healing was observed after 15 months of treatment

infection; the breast was free of masses and its shape was only minimally altered by scar formation.

\section{Discussion}

The main clinical manifestations of actinomycosis are slowly progressing, granulomatous and sinus-forming infections in the cervicofacial, thoracic, abdominal, and, in women, pelvic areas. Adjacent organs may be infiltrated but hematogenous dissemination has not been observed. The disease is four times more common in men; usually patients are in good health, free from underlying diseases [4].

Breast infections are relatively common, particularly in lactating women. They are often caused by bacteria of normal skin or oral flora, especially Staphylococcus aureus. Breast infections with Actinomyces spp. are rare and have mainly been described in premenopausal women [5]. They are classified as primary or secondary, depending on how the microorganisms reach the site of infection. Secondary actinomycosis of the breast results from pulmonary infection penetrating through the thoracic wall $[5,6]$. The more common primary form occurs when skin flora reach mammary tissue directly, possibly through cracks in the skin on or around the nipple. Risk factors for development of primary breast abscess include smoking, diabetes, and obesity [7]. Primary actinomycosis of the breast has most commonly been ascribed to A. israelii [4]. More recently, breast infections due to A. viscosus, A. turicensis, and $A$. radingae have been described $[8,9]$. Seven of the ten 
clinical strains in the first description of A. europaeus were isolated from human abscesses, one of which was a breast abscess in a 54-year-old woman [1]. Interestingly, sulfur granules have not been described in abscesses due to $A$. europaeus and were not found in this case [1, 2, 9]. Absence of sulfur granules has also been observed in infections caused by A. neuii, another Actinomyces species not commonly associated with classical actinomycosis [10].

The patient described here did not have pulmonary disease or evidence of osteomyelitis of the sternum or the ribs. It is plausible that actinomycetes reached mammary tissues through skin lacerations caused by post-sternotomy dressings.

Interestingly, the association of A. europaeus with other bacteria is more common than its isolation in pure culture. Clarridge et al. [11] found them associated with coagulasenegative staphylococci and corynebacteria and suggested that the normal niche of $A$. europaeus was the skin of the upper body. Sabbe et al. [2] found A. europaeus accompanied by a mixed anaerobic flora, as in the case described here. Attar et al. [8] also described two cases of actinomycosis of the breast (caused by strains other than $A$. europaeus) in association with anaerobic bacteria.

The most common clinical presentation of actinomycosis of the breast is recurrent retropapillary abscesses. Fistulas and purulent or bloody discharge from sinuses may occur. In the most advanced cases, fibrosis with local cicatrisation and distortion of the breast were reported [4]. In one series, two-thirds of the cases presented as persistent or recurrent breast abscesses and the other third presented with a breast lump suggestive of carcinoma [12]. Further differential diagnoses include tuberculosis, syphilis, rib osteomyelitis, and inflammatory carcinoma [5].

Recommended treatment for actinomycosis is intravenous penicillin at a daily dose of 18-24 million $U$ for 2-6 weeks, followed by oral penicillin or amoxicillin for a period of 6-12 months. Shorter treatment regimens may also be successful [13]. In the case presented here, however, treatment was given for 15 months, until full closure of all skin lesions. All reported cases of Actinomyces spp. of the breast have been successfully treated with a combination of surgical drainage and short-course antibiotic therapy [8, 9]. Surgical curettage is an important adjunctive treatment because of limited penetration of the antibiotics into the chronically indurated tissue of actinomycotic lesions and the dense aggregates of Actinomyces spp. known as sulfur granules.

A. europaeus seems to be susceptible in vitro to a wide range of $\beta$-lactam antibiotics which should be regarded as agents of first choice. Some A. europaeus have reduced susceptibility to tetracycline, ciprofloxacin, clindamycin, linezolid, and piperacillin/tazobactam [14]. The isolate reported here was fully susceptible to all $\beta$-lactam agents tested, and to clindamycin and tetracycline. In mixed infections with anaerobes amoxicillin-clavulanic acid may be preferred for initial treatment because of the notable $\beta$ lactamase activity of certain anaerobes.

Physicians and microbiologists should be aware that the clinical range of disease manifestations due to Actinomyces spp. may be widening and that new species may be causing particular disease manifestations. Treatment should be individualized and may need to be prolonged.

Acknowledgment The study was made possible in part through a collaborative project financed by the UBS Optimus Foundation and an educational research grant by Pfizer AG, Switzerland.

Conflict of interest None.

\section{References}

1. Funke G, Alvarez N, Pascual C, Falsen E, Akervall E, Sabbe L, Schouls L, Weiss N, Collins MD. Actinomyces europaeus sp. nov., isolated from human clinical specimens. Int J Syst Bacteriol. 1997;47:687-92.

2. Sabbe LJ, Van De Merwe D, Schouls L, Bergmans A, Vaneechoutte M, Vandamme P. Clinical spectrum of infections due to the newly described Actinomyces species A. turicensis, A. radingae, and A. europaeus. J Clin Microbiol. 1999;37:8-13.

3. Clinical and Laboratory Standards Institute (2007) Methods for Antimicrobial Susceptibility Testing of Anaerobic Bacteria; Approved Standard- Seventh Edition. CLSI document M11-A7 Clinical and Laboratory Standard Institute, Wayne, PA.

4. Davies JA. Primary actinomycosis of the breast. Br J Surg. 1951;38:378-81.

5. de Barros N, Issa FK, Barros AC, D'Avila MS, Nisida AC, Chammas MC, Pinotti JA, Cerri GG. Imaging of primary actinomycosis of the breast. AJR Am J Roentgenol. 2000;174:1784-6.

6. Pinto MM, Longstreth GB, Khoury GM. Fine needle aspiration of Actinomyces infection of the breast. A novel presentation of thoracopleural actinomycosis. Acta Cytol. 1991;35:409-11.

7. Gollapalli V, Liao J, Dudakovic A, Sugg SL, Scott-Conner CE, Weigel RJ. Risk factors for development and recurrence of primary breast abscesses. J Am Coll Surg. 2010;211:41-8.

8. Attar KH, Waghorn D, Lyons M, Cunnick G. Rare species of actinomyces as causative pathogens in breast abscess. Breast $\mathrm{J}$. 2007;13:501-5.

9. Capobianco G, Dessole S, Becchere MP, Profili S, Cosmi E, Cherchi PL, Meloni GB. A rare case of primary actinomycosis of the breast caused by Actinomyces viscosus: diagnosis by fineneedle aspiration cytology under ultrasound guidance. Breast $\mathrm{J}$. 2005;11:57-9.

10. von Graevenitz A: Actinomyces neuii: review of an unusual infectious agent. Infection. $2011 \mathrm{Feb} 22$. [Epub ahead of print] PMID: 21340579.

11. Clarridge JE 3rd, Zhang Q. Genotypic diversity of clinical Actinomyces species: phenotype, source, and disease correlation among genospecies. J Clin Microbiol. 2002;40:3442-8. 
12. Jain BK, Sehgal VN, Jagdish S, Ratnakar C, Smile SR. Primary actinomycosis of the breast: a clinical review and a case report. J Dermatol. 1994;21:497-500.

13. Sudhakar SS, Ross JJ. Short-term treatment of actinomycosis: two cases and a review. Clin Infect Dis. 2004;38:444-7.
14. Smith AJ, Hall V, Thakker B, Gemmell CG. Antimicrobial susceptibility testing of Actinomyces species with 12 antimicrobial agents. J Antimicrob Chemother. 2005;56:407-9. 